\title{
Educação em Ciências na Escola Democrática e as Relações Étnico-Raciais
}

\section{Education in Science in Democratic School and Racial- Ethnic Relations}

\author{
Bárbara Carine Soares Pinheiro ${ }^{\circledR}$ Brasil
}

O presente artigo tem como objetivo, a partir de uma revisão bibliográfica nas principais referências da área etnocêntrica e decolonial nas ciências no Brasil apontar caminhos para a educação em ciências naturais, abordando as relações étnico-raciais como eixo norteador. Neste sentido, revisamos a literatura das teorias decoloniais com o intuito de compreender do que se trata o processo de descolonização de saberes, bem como de compreendermos o que nos trouxe até este estágio epistêmico, cosmogônico e global eurocêntrico que reduziu nossas existências e produções intelectuais a um padrão de referência único e universalizado. Para tal, apresentamos produções científicas africanas pré-diaspóricas, bem como cientistas contemporâneos que destoam desses padrões socialmente impostos, visando ampliar a imagética acerca da noção de ciência e pautar a importância de se discutir representatividades diversas nos espaços de poder, dentre eles o de produção acadêmica. Ressalto que a escrita deste texto se dará em afro perspectiva por meio da proposição teórico-metodológica cunhada pela escritora Conceição Evaristo, denominada escrevivência. Por esta razão imprimo nestas palavras o que leio, penso e sinto. Realizo não só formulação e reformulações a partir de outros e outras, como também parto deste meu lugar de mulher negra brasileira nordestina que atua na área de Ensino de Química.

Palavras-chave: Decolonialidade; Relações Étnico-Raciais; Ensino de Ciências.

Based on a bibliographical review of the main references on the ethnocentric and decolonial fields in the sciences in Brazil, the present article aims to point out ways for natural sciences education, approaching ethnic-racial relations as the "guiding axis". In this sense, we review the literature of decolonial theories in order to understand not only what the process of decolonization of knowledge is about, but also what has brought us to this epistemic, cosmogonic and global Eurocentric stage that has reduced our existences and intellectual productions to a single universal standard of reference. To this end, we present pre-diasporic African scientific productions, as well as contemporary scientists who disregard these socially imposed standards, aiming to expand the notion of science and to guide the importance of discussing diverse representations in the spaces of power, 
among them that of academic production. I emphasize that the writing of this text will be driven towards afroperspective, through the theoretical-methodological proposition coined by the writer Conceição Evaristo, denominated Escrevivência ("Writexperience"). For this reason, I print in these words what I read, I think and I feel. Not only I make formulation and reformulations from other authors, but also I start from this place of a northeastern black Brazilian woman who works in the field of chemistry education.

Keywords: Decoloniality; Ethnic-Racial Relations; Science Teaching.

\section{Introdução}

Nos últimos anos, tenho refletido acerca da questão das relações étnico-raciais no Ensino de Ciências, mais precisamente no Ensino de Química, muito inspirada por pesquisadores/as brasileiros/as como Benite, Silva, e Alvino, (2017), Cunha Junior, (2010), Machado, e Loras, (2017); Nascimento, (1996), Pinheiro, (2016), Rosa, (2016), Santos, Rodrigues Filho, e Amauro, (2016), Verrangia, (2010). Nesse processo, tenho vivenciado a experiência de repensar a minha prática pedagógica e investigativa a partir da contestação da universalidade das bases epistemológicas às quais fui submetida e, por elas nesse processo de apropriação e auto construção identitária, forjada.

Nesse sentido, algumas questões passaram a me inquietar de um modo mais latente no Ensino de Ciências em geral, tais como:

- O que é a ciência? Quem circunscreveu os seus critérios de demarcação? A partir de qual perspectiva essa racionalidade foi universalizada?

- Por que o padrão de cientista presente no imaginário coletivo é o homem cis branco heterossexual da área das ciências exatas ou naturais?

- Que mito é esse, que nós facilmente acreditamos, de que a Grécia possui a primazia de gestar quase todas as formas de epistemes disseminadas nos espaços acadêmicos?

Aprendemos nos espaços de formação pedagógica e acadêmica que a Filosofia surge na Grécia com Thales de Mileto (624-546 a.C.), que a Matemática surge na Grécia com o já citado Thales, bem como com Pitágoras (570-495 a.C.) e Euclides (300 a.C.-), que a Literatura e asArtes surgem na Grécia com as tragédias gregas vinculadas às obras de Hesiodo (750-650 a.C.) e Homero (850 a.C.-), que a História surge na Grécia com Heródoto (485-425 a.C.), que a Medicina surge na Grécia com Hipócrates (460- 370 a.C.), que a Geografia surge na Grécia com Eratóstenes de Cirene (276-194 a.C.), que a Biologia surge na Grécia com a classificação dos seres vivos proposta por Aristóteles (384-322 a.C.), que o Direito surge na Grécia com a República de Platão (428-348 a.C.), que a Química surge na Grécia com a tensão entre os continuistas Heráclito (540 a.C.-470), Anaximandro (610-546 a.C.), Anaximenes (588-524), Thales de Mileto, Empédocles (490 a.C.-430 a.C.), dentre outros, em contraposição a perspectiva dos descontinuistas defensores da hipótese atômica Leucipo (-370 a.C.), Demócrito (460 -370 a.C) e Epicuro (341-270 a.C.)... eu poderia ir adiante expondo vários outros 
exemplos de gênese epistêmica grega. Mas o importante dessa exaustiva exposição é problematizarmos por que em um planeta tão grande e diverso, com várias civilizações anteriores à Grécia, tudo ficou tão estático, apático e sem vida, esperando a Grécia surgir e trazer luz ao mundo?

Além da civilização grega, podemos destacar na antiguidade a existência de vários outros grandes povos como os fenícios, sumérios, os chineses, os maias, os astecas, os incas, os romanos, os egípcios, entre outros. No caso específico do continente africano que, no referido período, não era um continente e não se tinha essa noção atual de um todo homogêneo, existiram muitos outros impérios além de Kemet (como os/as africanos/as chamavam o antigo Egito) a exemplo de Axum, Meroé, Núbia, Numídia, a Terra de Punt, o Império de Kush, o Império Ashanti e o Império de Gana, Daomé, dentre outros. Vale destacar que Kemet, ao contrário do que muitos pensam não fica na Europa, trata-se de uma civilização africana e negra (Diop, 1983).

Uma breve leitura da história nos mostra que o Antigo Egito (3200 a.C332 d.C.) tem origem bem anterior à da Grécia antiga (1200 a.C.-529 d.C.) e que a própria humanidade surge no continente africano ${ }^{1}$. Como imaginar que esses povos se mantiveram improdutivos material e intelectualmente por milênios e que só merecem um capítulo na história da humanidade a partir do episódio macabro da diáspora africana, traduzido por nós como a desumanização, o genocídio e o sequestro humano (de seus corpos e de suas memórias)?

Infelizmente, é muito comum em nosso país, jovens em geral terem acesso à história da população africana no mundo apenas a partir do tráfico de seres humanos escravizados (Munanga, \& Gomes, 2006), comumente chamados de "escravos", um termo profundamente equivocado, pois remete a uma vinculação ontológica, a uma condição de existência. No entanto, pessoas não nascem escravas, elas são escravizadas.

Muito frequentemente, o primeiro contato que estudantes têm nas escolas com um corpo negro é em um navio tumbeiro, ou negreiro como comumente o chamam. Esse é o traço fundamental constitutivo da nossa identidade ancestral. Aprendemos na escola que viemos de "escravos". Obviamente que alguém que vem de "escravos" não se sente privilegiado em sua origem e constrói uma relação psíquica causal e direta que justifica seu atual rebaixamento social, sua não detenção de bens materiais e imateriais é justificada pela sua relação com sua origem. Entretanto, pessoas negras não surgiram no mundo com a escravidão, ao contrário do que nos foi ensinado nas escolas.

É preciso educar a juventude mostrando narrativas diversas e decoloniais dos diferentes marcos civilizatórios que nos constituíram. Basta de uma narrativa histórica eurocêntrica que reduz a existência ancestral de outros povos ao abismo do esquecimento e coloca a Europa no topo do progresso e das civilizações. Como é possível estudarmos ainda hoje nas escolas uma história do Brasil na qual o marco fundacional é a chegada de europeus? Como é possível estudarmos uma história geral marcada

1 A Arqueologia e a Paleontologia nos apontam que o fóssil humano mais antigo encontrado na terra possui cerca de 300 mil anos e foi achado em escavações realizadas no leste do continente africano, atual Marrocos. 
por transições temporais pautadas na alteração dos modos de produção em países do referido continente? Na história dita antiga, marcada pelo modo de produção escravista, o que acontecia nas Américas? O escravismo era a prática econômica norteadora dos nossos povos originários? Onde ocorreu o sistema feudal nas Américas? $\mathrm{Na}$ ascensão do feudalismo para o capitalismo vivemos a prática escravagista e não encontramos trabalho assalariado, mais valia nas nossas vivências ${ }^{2}$. Que história geral é essa que não nos cabe em sua universalidade?

A racionalidade europeia efetivou a leitura oficial da história da humanidade levando em conta somente a experiência do continente e universalizando reflexões alheias às múltiplas possibilidades do conhecer (Quijano, 2005). A história tem uma direção, um sentido único em direção ao progresso, à modernização. Tudo que é assimétrico em relação a esse avanço e desenvolvimento é produzido como atrasado, subdesenvolvido, primitivo. Segundo Dussel (1993), esta universalização da história é um dos vários mitos da modernidade, faz-se necessário desconstruirmos tais perspectivas visando não só o cumprimento da Lei de Diretrizes e Bases da Educação Nacional, assim como das legislações específicas, a exemplo das leis 10.639/2003 e 11645/2008, mas fundamentalmente resgatar narrativas, produções intelectuais e referências positivas ancestrais.

\section{Metodologia}

Este artigo tem como objetivo, a partir de uma revisão bibliográfica das principais referências da área etnocêntrica e decolonial das ciências no Brasil, apontar caminhos para a educação em ciências naturais, abordando as relações étnico-raciais como eixo norteador. A revisão bibliográfica consistiu em uma análise no acervo de publicações correntes na referida área de estudo, a fim de buscar respostas ou um maior conhecimento sobre a temática das relações étnico-raciais e sua articulação com a educação em ciências. Neste sentido, buscou-se publicações de pesquisadores/as brasileiros/as que contemplassem as áreas da Química, Física, Biologia, Matemática e História (das Ciências) e que apresentassem tal perspectiva. Temporalmente a pesquisa foi projetada para os quinze anos de vigência da Lei 10.639/2003, ou seja, do ano de 2003 a 2018.

As publicações foram livros, artigos publicados em revistas e em anais de eventos, bem como em dissertações e teses. Nestas obras busquei identificar alguns elementos que favorecessem a construção de uma narrativa histórica africana e afrodiáspórica, a partir da produção intelectual científica-tecnológica do povo negro no mundo desde o surgimento da humanidade até os dias atuais, buscando, assim, desconstruir mitos acerca da intelectualidade de pessoas negras. Como a produção na área não é vasta e

2 Vale ressaltar que não há desconexão do escravagismo nas Américas com o sistema capitalista, é justamente a escravidão e a expropriação das terras americanas que vai ocasionar a sangrenta acumulação primitiva do capital europeu. As grandes fortunas mundiais têm muito sangue na sua história e a categoria de raça foi basilar para o sistema classista o qual vivemos. 
relativamente recente, os textos selecionados, que nos ajudaram a compor essa narrativa foram: Benite, Silva, e Alvino (2017), Cunha Junior (2010), Machado, e Loras (2017), Pinheiro (2016), Pinheiro, e Rosa (2018), Santos, Rodrigues, e Amauro (2016), Silva (2013), Silva, e Pinheiro (2018). Quanto aos/as cientistas negros/as selecionados/ as, apoiei-me nas personalidades por mim apresentadas semanalmente na página de divulgação científica negra na rede social Instagram, denominada "Descolonizando Saberes”. Busquei selecionar os/as cientistas pela relevância da sua produção, bem como pela localidade não apenas focada nos EUA.

\section{Decolonialidade}

A noção de decolonialidade parte da premissa da negação da colonialidade, $o$ pressuposto é que deixamos de ser colônia de Portugal em 1822, mas os padrões de colonialidade permanecem fortes em nossa vida cotidiana até os dias de hoje. A colonialidade é conceituada por Aníbal Quijano como o padrão de poder criado pelo "colonizador"3 para controlar a subjetividade dos "povos colonizados" (Quijano, 2010),

Tocamos nossa existência chamando a Europa de "o velho mundo" (mesmo sabendo que a humanidade surgiu na África); quando viajamos para a Europa dizemos que vamos ao berço das civilizações (mesmo sabendo que no mundo existem civilizações anteriores), propagamos a noção de que a universidade surge na Europa em Bolonha (uma fácil busca no Google nos revela que a primeira universidade do mundo é a universidade de Al-Karaouine em Fes no Marrocos, Leste africano); julgamos que europeus são mais avançados e civilizados a ponto de que nossos doutorados sanduiche e nossos pós-doutorados corriqueiramente precisam ser feitos na Europa mesmo que seja uma temática profundamente endógena e com grandes centros de referência no Brasil; acreditamos que a Europa é o padrão de ciência e intelectualidade, assim sendo todo fenótipo fora do padrão europeu (a exemplo de pessoas negras e indígenas) é caracterizado como não desenvolvedor de ciência, mas de conhecimentos populares, de não intelectual, mas destinado a trabalhos braçais. Esses são alguns dos vários padrões de colonialidade que atualmente estão fortemente presentes em nossas vidas. Mas de onde vem essa forma de pensamento?

De acordo com Fanon (2008) a colonialidade, que é articulada à construção do conceito de raça, se manifesta em três dimensões, a saber: a colonialidade do ser, do saber e do poder.

A colonialidade do ser parte da modulação da existência dos indivíduos. A colonialidade do ser é a dimensão ontológica da colonialidade que se afirma na violência da negação do Outro (Carneiro, 2005). Decorrente do eurocentrismo moderno, eminentemente antropocêntrico, produtor de estereótipos e definidor de critérios de humanidade. Por sua cor e raízes ancestrais, os seres diferentes do padrão europeu ficam marcados pela inferiorização, subalternização, desumanização, pela não existência,

3 Essa perspectiva de colonizador e colonizado segue a narrativa do dominante, talvez povos africanos não chamassem os europeus de colonizadores, talvez de assassinos, de sequestradores, dentre outros. 
tornadas invisíveis suas racionalidades e a dignidade de sua humanidade. Então, a colonialidade do ser se consolida através da violência ontológica projetada para destruir imaginários, identidades, sentidos, existências (Melo, 2019).

Para Fanon (2008), o negro é uma construção do branco. A branquitude europeia em um dos variados mitos da modernidade inventou a noção de raças, criando graus hierárquicos entre estas e, inclusive, retirando a humanidade desse Outro forjado no caldeirão colonial moderno. Criou-se não só a noção de raça negra como aquela atrasada, isenta de características humanas, sexualizada e animalizada, apagando toda a memória desses povos de grandes inventos e grandes impérios, e reduziu-a a este lugar, melhor, a este não lugar. A branquitude construiu seus padrões de superioridade, bem como inventou um padrão de subalternidade e subserviência negro, que até os dias de hoje marcam nossas construções psíquicas acerca de quem somos, de onde viemos e do que podemos vir a ser. "Por mais dolorosa que possa ser esta constatação, somos obrigados a fazê-la: para o negro, há apenas um destino e ele é branco" (Fanon, 2008. p. 28)

No âmbito da colonialidade do poder, Quijano (2010) nos aponta para as relações de poder construídas a partir do projeto da colonização europeia na América que articulou o colonialismo imperial e a ciência ocidental, através da ideia de raça como instrumento de classificação hierárquica e controle social. Na colonialidade do poder, a raça superior, constituída de homens brancos, cristãos, europeus, tem direito à dominação e as demais raças inferiores são subjugadas.

A colonialidade do saber, por sua vez, impõe o saber europeu como marco referencial de conhecimento verdadeiro e avançado frente a todos os outros tipos de conhecimento que são tomados como inferiores, desconsiderando assim a existência de outras racionalidades e formas de conhecer e interpretar o mundo. Dessa maneira, a ciência moderna tem a concessão do monopólio da distinção universal entre o verdadeiro e o falso. A ciência moderna, transformada em único conhecimento válido e, portanto, enquadrando tudo aquilo que está fora do limite do rigor científico como ignorante. Trata-se de um saber que se coloca como modelo que tem suas bases no eurocentrismo como monopolizador da razão, que opera pela violência epistêmica que gera uma subalternização de saberes outros, calcados em lógicas distintas (Mignolo, 2008).

Haveria ainda, de acordo com Walsh (2008), uma colonialidade cosmogônica marcada pela separação entre indivíduos e natureza, o que remete a um afastamento da natureza e a desvinculação afetiva e existencial em relação a esta. Esta dicotomização propicia uma disponibilização da natureza para sua descontrolada e irracional exploração. Esta colonialidade cosmogônica é algo muito vinculado às construções dos padrões existenciais europeus, visto que outros povos, a exemplo de povos indígenas e africanos, sempre possuíram uma relação indissociável com a natureza, sentindo-se parte integrante desta; de modo que negligenciar a natureza e abrir mão do seu cuidado significa abandonar a si mesmos e mesmas.

Pensar estratégias de superação destes padrões de colonialidade faz-se profundamente necessário para nos reconciliarmos com nossas histórias, epistemologias 
e identidades. Trata-se de um contínuo processo de desconstruir-se para se permitir reconstruir a partir de novas relações afetivas consigo mesmo.

\section{Descolonizando saberes científicos}

Historicamente, a Ciência foi reconhecida com seu nascimento no continente europeu na modernidade, tendo sido negados todos os saberes produzidos por povos ancestrais não europeus, mas que foram fundamentais para a estruturação do conhecimento greco-romano. Neste sentido, as representações de cientistas reproduzidas em manuais de ciências em geral é a de homens cis, heterossexuais e brancos. Em outros termos, sendo a ciência um espaço de poder a representação de seu desenvolvimento foi associada à imagem de sujeitos sociais aceitos e hegemônicos. Assim sendo, todos que estavam fora desses padrões, mas que buscavam se vincular ao processo de desenvolvimento do conhecimento científico, eram rechaçados, inferiorizados e silenciados (Pinheiro, \& Rosa, 2018).

Não existem relatos de que os europeus enviassem engenheiros/as e técnicos/ as altamente especializados/as para atuarem no bom funcionamento de engenhos ou mesmo para improvisar desvios em túneis em minas ou em qualquer outro ambiente de trabalho executado por pessoas negras (Silva, 2013). Segundo Cunha-Junior (2010), foram esses seres humanos escravizados que tiveram que "engenhar", consertar pequenos detalhes de engenhos quebrados, resolver como desviar um túnel de uma mina caso uma pedra estivesse no caminho, pensar em pequenos e importantes detalhes na colheita da cana e do café, e com isso aumentar a riqueza da nação escravocrata diminuindo assim a dor dos açoites. Em outras palavras, durante séculos nesse país, pessoas negras foram as principais cientistas e técnicas porque conseguiram manter um modo de produção, cujos detalhes técnicos eram por eles pensados e executados. A sociedade brasileira herdou a riqueza oriunda da ação técnica e científica de pessoas escravizadas.

Isto porque o conhecimento tecnológico estava presente em diversos ambientes culturais e sociais da África antiga e estes povos, que foram sequestrados e escravizados, lançaram mão dos seus saberes ancestrais para sobreviverem nestas terras (Silva, 2013).

Os conhecimentos médico, químico, farmacológico, arquitetônico, artístico, culinário, sanitário, astronômico, matemático (os cálculos matemáticos, que inclusive propiciaram a construção de pirâmides) eram em graus diferenciados, parte deste continente. A medicina egípcia, por exemplo, produzia conhecimento a partir dos experimentos e estudos voltados para o interior do organismo humano, elaborados em função da prática da mumificação, do embalsamento dos corpos dos faraós e de pessoas influentes desta sociedade (Nascimento, 1996). Muito anterior ao avanço moderno da medicina europeia, a medicina egípcia já abria corpos e conhecia os órgãos, algo que só ocorreu na Europa com o rompimento em relação à racionalidade cristã medieval, que previa uma vinculação entre corpo e alma.

O conhecimento médico não esteve situado apenas no norte africano. Na região que hoje compreende Uganda, país da África Central, encontramos o saber antigo 
dos Banyoro que já faziam a cirurgia de cesariana antes do ano do século XIX quando um cirurgião inglês conheceu e aperfeiçoou essa técnica (Machado, \& Loras, 2017). O conhecimento médico cirúrgico antigo e tradicional na África, também operava os olhos removendo as cataratas. Essa técnica foi encontrada no Mali e no Egito, bem como há cerca de 4.600 anos, neste último país mencionado, já se fazia a cirurgia para a retirada dos tumores cerebrais e, recentemente, foram encontradas estruturas ósseas nas escavações das pirâmides de Gizé, que revelaram possíveis cirurgias cranianas e ortopédicas em trabalhadores das pirâmides. Os Banyoro, também, detinham há séculos o conhecimento acerca da vacinação e da farmacologia, logo, as técnicas médicas e terapêuticas africanas não estavam voltadas, somente, para o mundo místico; eles tinham conhecimentos científicos para a observação atenta do paciente (Nascimento, 1996).

Se levarmos em consideração que a humanidade surgiu na África e, com ela, as primeiras civilizações, é extremamente plausível se pensar que foram estes primeiros humanos que desenvolveram formas de produção e reprodução de conhecimento. Deuse na África: o desenvolvimento da cerâmica, a tinturaria a partir da manipulação de óxidos metálicos, a produção de bebidas alcoólicas (Silva, \& Pinheiro, 2018), a química de conservação da matéria por meio dos processos de mumificação, a fundição de metais e produção de ligas a partir do desenvolvimento de altos fornos (Fluzin, 2014), a primeira revolução tecnológica da humanidade, a passagem de caçador e coletor de frutos e raízes para a agricultura e pecuária. A agricultura africana, no vale do rio Nilo, tem cerca de 18 mil anos, sendo duas vezes mais antiga do que a do sudoeste asiático (Cunha Junior, 2010). A pecuária apareceu há 15 mil anos, perto da atual Nairobi (Quênia), sendo uma técnica sofisticada de domesticação de animais que deve ter se espalhado para os vales dos rios Tigre e Eufrates séculos depois. Populações africanas presentes nos limites do deserto do Saara e do Sudão legaram à escrita a humanidade. Os sistemas de escrita dos Akan e dos Manding originaram a escrita egípcia e meroítica, sendo que esta última baseou o nosso formato de escrita (Machado, e Loras, 2017).

Já na contemporaneidade temos muitos inventos e conhecimentos produzidos por pessoas negras na diáspora, alguns destes elencados na Figura 1.

\begin{tabular}{|l|l|l|}
\hline $\begin{array}{l}\text { Algumas/alguns } \\
\text { Cientistas }\end{array}$ & Imagem & Contribuição científico-tecnológica \\
\hline $\begin{array}{l}\text { Alice Augusta } \\
\text { Ball }\end{array}$ & Cura para a hanseníase. \\
$(1892-1916)$ & & \\
EUA &
\end{tabular}

Figura 1. Alguns cientistas negros e negras e suas respectivas contribuições científico-tecnológicas ${ }^{4}$ (continua)

4 Todas as imagens do quadro foram extraídas do Google imagens 


\begin{tabular}{|c|c|c|}
\hline $\begin{array}{l}\text { Patrícia Bath } \\
(1942-) \\
\text { EUA }\end{array}$ & (1) & $\begin{array}{l}\text { Criou dispositivo a laser utilizado em cirurgias de } \\
\text { cataratas. }\end{array}$ \\
\hline $\begin{array}{l}\text { Sebastião } \\
\text { Oliveira } \\
(1918-2005) \\
\text { Brasil }\end{array}$ & & $\begin{array}{l}\text { Catalogação e descrição entomoçógica das famílias } \\
\text { de mosquitos Chironomidae e Culicidae }\end{array}$ \\
\hline $\begin{array}{l}\text { Francine Ntoumi } \\
(1961-) \\
\text { Congo }\end{array}$ & $=\frac{1}{0^{2}}(y)=$ & $\begin{array}{l}\text { Criação de redes para combater doenças infecciosas } \\
\text { em toda a África }\end{array}$ \\
\hline $\begin{array}{l}\text { Lewis Latimer } \\
(1948-1928) \\
\text { EUA }\end{array}$ & & Patenteou a lâmpada de filamento de carbono \\
\hline $\begin{array}{l}\text { Marcelle Soares } \\
\text { Santos } \\
(1982-) \\
\text { Brasil }\end{array}$ & & $\begin{array}{l}\text { Realiza pesquisas sobre a natureza da expansão } \\
\text { acelerada do universo usando dados de poderosos } \\
\text { telescópios }\end{array}$ \\
\hline $\begin{array}{l}\text { Segenet Kelemu } \\
(1957-) \\
\text { Etiópia }\end{array}$ & & $\begin{array}{l}\text { Avanços na patologia molecular de plantas } \\
\text { reproduzindo plantas mais resistentes às alterações } \\
\text { climáticas }\end{array}$ \\
\hline $\begin{array}{l}\text { Denise Fungaro } \\
(1959-) \\
\text { Brasil }\end{array}$ & 17 & $\begin{array}{l}\text { Desenvolveu método para a produção de sílica gel e } \\
\text { nanosílica de alta pureza com biomassa de cana de } \\
\text { açúcar }\end{array}$ \\
\hline $\begin{array}{l}\text { Yacouba } \\
\text { Sawadogo } \\
(1946-) \\
\text { Burkina Faso }\end{array}$ & & $\begin{array}{l}\text { Desenvolveu técnicas de reflorestamento e de } \\
\text { conservação do solo }\end{array}$ \\
\hline
\end{tabular}

Figura 1. Alguns cientistas negros e negras e suas respectivas contribuições científico-tecnológicas (continuação) 


\begin{tabular}{|c|c|c|}
\hline $\begin{array}{l}\text { Quarraisha } \\
\text { Abdool Karim } \\
(1960-) \\
\text { África do Sul }\end{array}$ & & $\begin{array}{l}\text { Desenvolvimento de um gel microbicida e também } \\
\text { um anel vaginal que reduzem os riscos de infecção } \\
\text { do HIV em } 40 \%\end{array}$ \\
\hline $\begin{array}{l}\text { Wangari Muta } \\
\text { Maathai } \\
(1940-2011) \\
\text { Quênia }\end{array}$ & & $\begin{array}{l}\text { Desenvolveu técnicas de conservação ambiental. } \\
\text { Foi bióloga e foi primeira mulher africana a receber } \\
\text { o prêmio Nobel da paz }\end{array}$ \\
\hline $\begin{array}{l}\text { Herbert Clay } \\
\text { Scurlock } \\
(1875-1952) \\
\text { EUA }\end{array}$ & & Aplicação da radioterapia no tratamento do câncer \\
\hline $\begin{array}{l}\text { Vivien Theodore } \\
\text { Thomas } \\
(1910-1985) \\
\text { EUA }\end{array}$ & & $\begin{array}{l}\text { Desenvolveu tratamento para a síndrome dos bebês } \\
\text { azuis }^{5}\end{array}$ \\
\hline $\begin{array}{l}\text { Joana D’arc Félix } \\
(1963-) \\
\text { Brasil }\end{array}$ & & $\begin{array}{l}\text { Desenvolvimento de pele similar à pele humana } \\
\text { para ser utilizada em queimaduras e transplantes }\end{array}$ \\
\hline $\begin{array}{l}\text { Gladys Mae West } \\
(1931-) \\
\text { EUA }\end{array}$ & & $\begin{array}{l}\text { Teve papel fundamental no desenvolvimento da } \\
\text { tecnologia GPS }\end{array}$ \\
\hline
\end{tabular}

Figura 1. Alguns cientistas negros e negras e suas respectivas contribuições científico-tecnológicas (continuação)

5 No coração do feto humano a separação entre os átrios é incompleta e há também um ligação entre a artéria pulmonar e a artéria aorta. Essas comunicações desviam o sangue dos pulmões, que não são funcionais no feto, pois as trocas de gases ocorrem através da placenta. Quando o bebê nasce, inicia-se a respiração pulmonar e essas comunicações se fecham. Entretanto, em alguns casos, isso pode não acontecer e a oxigenação do sangue fica prejudicada, resultando na doença conhecida como bebê azul. 


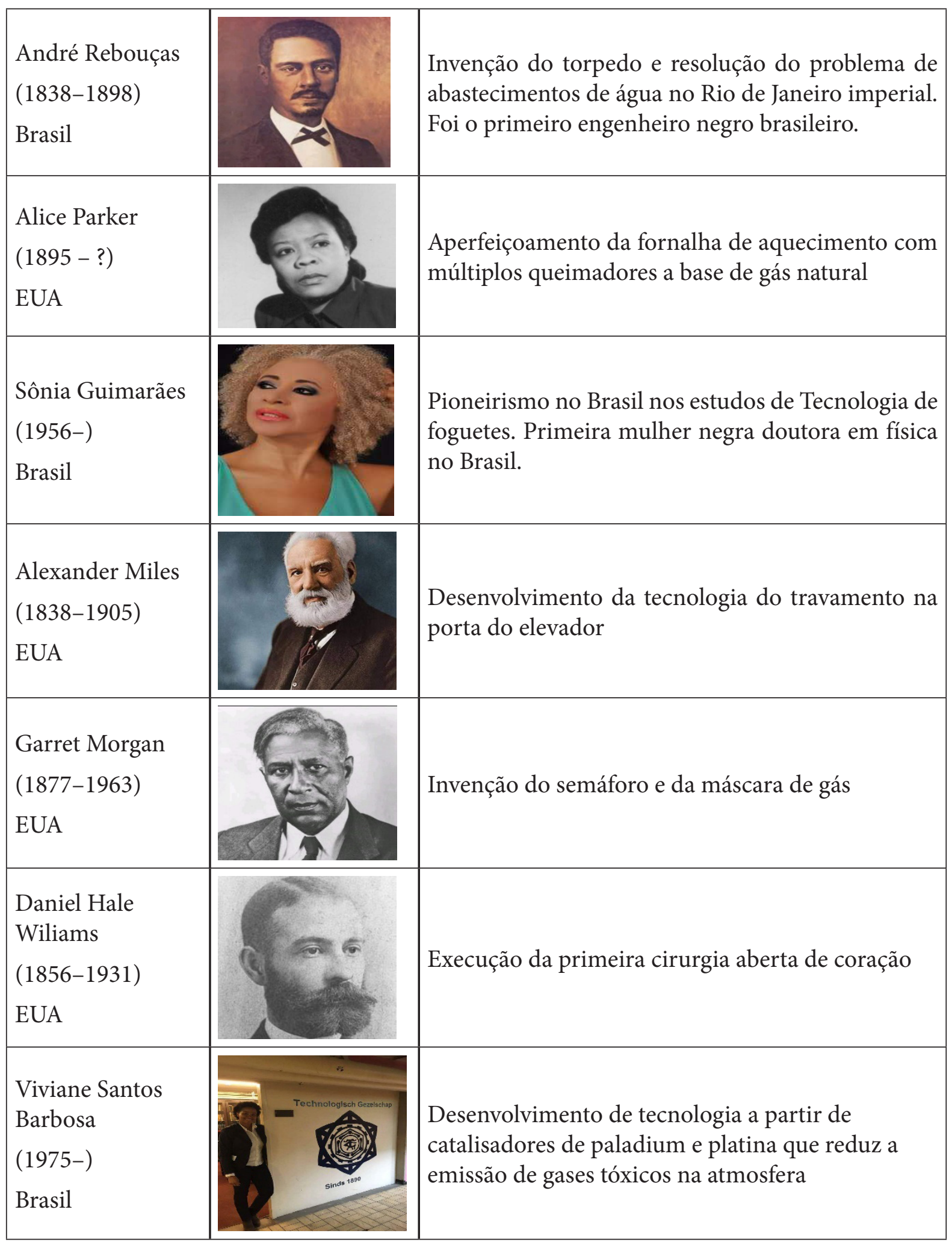

Figura 1. Alguns cientistas negros e negras e suas respectivas contribuições científico-tecnológicas (continuação) 


\begin{tabular}{|c|c|c|}
\hline $\begin{array}{l}\text { Charles Henry } \\
\text { Turner } \\
(1867-1923) \\
\text { EUA }\end{array}$ & & $\begin{array}{l}\text { Apresentação de evidências empíricas que provam } \\
\text { que insetos conseguem escutar e distinguir tons, } \\
\text { que baratas aprendem por tentativa e erro e que } \\
\text { abelhas podem enxergar cores }\end{array}$ \\
\hline $\begin{array}{l}\text { Victor Mancir } \\
(1986-) \\
\text { Brasil }\end{array}$ & 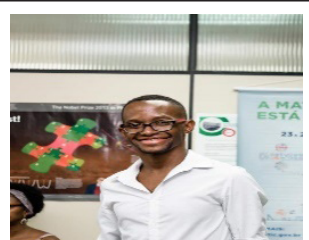 & $\begin{array}{l}\text { Potencialização da técnica de XPS no Brasil, } \\
\text { ampliando sua aplicação para isolantes, condutores } \\
\text { e semicondutores. }\end{array}$ \\
\hline $\begin{array}{l}\text { Katherine } \\
\text { Johnson } \\
(1918-) \\
\text { EUA }\end{array}$ & & $\begin{array}{l}\text { Realização de cálculos que garantiram que o Apolo } \\
11 \text { aterrissasse em } 1960 \text { na lua. Conhecida como } \\
\text { computador de saia na NASA. }\end{array}$ \\
\hline $\begin{array}{l}\text { Philip Emeagwali } \\
(1954-) \\
\text { Nigéria }\end{array}$ & & $\begin{array}{l}\text { Desenvolvimento do primeiro programa } \\
\text { computacional a aplicar uma abordagem de } \\
\text { pseudo-tempo à modelagem de reservatórios. }\end{array}$ \\
\hline $\begin{array}{l}\text { Valerie Thomas } \\
(1943-) \\
\text { EUA }\end{array}$ & & $\begin{array}{l}\text { Desenvolvimento da tecnologia } 3 \mathrm{D} \text { a partir do } \\
\text { trabalho com espelhos côncavos criando a ilusão } \\
\text { de objetos tridimensionais }\end{array}$ \\
\hline $\begin{array}{l}\text { Otis Boykin } \\
(1920-1982) \\
\text { EUA }\end{array}$ & & $\begin{array}{l}\text { Aprimoramento do marca-passo, adicionando um } \\
\text { controle eletrônico ao mecanismo. Essa melhoria } \\
\text { no aparelho salva vidas até hoje. }\end{array}$ \\
\hline
\end{tabular}

Figura 1. Alguns cientistas negros e negras e suas respectivas contribuições científico-tecnológicas (continuação)

Confesso que foi cansativa, mas ao mesmo tempo extremamente prazerosa a produção de tal quadro. Prazerosa pela visibilização necessária de corpos negros nas ciências naturais e cansativa, pois muitos são os nomes e foi difícil estabelecer critério de seleção visto que são muitas pessoas negras que produziram importantes conhecimentos em diferentes áreas que impulsionaram o desenvolvimento das ciências e da tecnologia. Entretanto, mesmo com esta vastidão de produção científica africana e 
afrodiaspórica (produção de pessoas negras espalhadas pelo mundo pós processo escravagista) a noção de cientista que nos foi apresentada foi aquela de homens brancos europeus de classe social favorecida. Por esta razão, a Figura 1 nos coloca em condição de profunda reflexão diante destas produções e destas imagens.

Precisamos superar este estado de racismo institucional e colonialidade epistêmica que coloca corpos e mentes brancas em um lugar de brilhantismo intelectual e reduz pessoas negras e de outras etnias a condições subalternas, de ausência de inteligência acadêmica e de propensão, unilateral, a trabalhos braçais. Viemos das primeiras civilizações do planeta, produzimos as primeiras formas de conhecimento e, até os dias de hoje, mesmo mediante a todo processo de sequestro de memória e de subalternização social, seguimos rompendo barreiras e acessando espaços de poder que nos são negados, como a ciência.

\section{Considerações finais}

Este artigo teve como objetivo a partir de uma revisão bibliográfica nas principais referências da área etnocêntrica e decolonial nas ciências no Brasil apontar caminhos para a educação em ciências naturais, abordando as relações étnico-raciais como eixo norteador. Penso que de fato, o caminho só se faz caminhando, entretanto, estratégias podem ser apresentadas como formas de trazer alguns acúmulos existentes na área.

Penso que podemos apresentar propostas didáticas para a efetivação do trato das relações étnico-raciais no ensino de ciências como fazem alguns autores e algumas autoras (Pinheiro, \& Silva, 2008; Pinheiro, \& Rosa, 2018; Santos, Rodrigues Filho, \& Amauro, 2013; Silva, Alvino, Santos, Santos, \& Benite, 2017; Silva, Garcia, \& Pinheiro, 2018; Silva, \& Pinheiro, 2018). No entanto, julgo que fundamentalmente, independente de articularmos estes acúmulos com o conteúdo de sala de aula ou não, precisamos resgatar a dignidade e a real humanidade de pessoas negras por meio da socialização de uma autoimagem positiva na juventude deste país.

Como implicação deste trabalho para a área de ensino ciências da natureza e matemática, aponto a necessidade que temos de apresentar outras narrativas históricas na qual cientistas não sejam estereotipados e tenhamos destacadas a produção científica e tecnológica de pessoas negras no Brasil e no mundo a fim de pensarmos que lugar é esse que nos foi reservado dentro da história hegemônica. Neste sentido, o artigo pauta a visibilização dessas produções na escola básica e no ensino superior com a finalidade de problematizar padrões impostos, socializar conhecimentos e processos produtivos intencionalmente silenciados e apagados.

Pessoas negras, assim como todos os seres humanos, podem alcançar seus objetivos, pois de fato todos somos humanos e igualmente potenciais. Contudo, nada adianta essa constatação estar apenas no campo discursivo reforçado por uma ciência genética que higieniza esta abordagem na atualidade, mas que num passado próximo foi responsável por reduzir essa humanidade com relação a pessoas negras, atribuindoas geneticamente características sociais de modo patologizado, tais como: negro é 
preguiçoso, pouco inteligente, propenso ao crime, etc. Tais características fazem com que pessoas afirmem que baiano é preguiçoso (Bahia é o estado mais negro do Brasil e Salvador a Cidade mais negra fora do continente africano), que pessoas negras sejam encarceradas em massa, que apertemos nossas bolsas na rua quando passamos por alguém com este fenótipo, que achemos o nosso estudante negro tem naturalmente mais dificuldade de aprendizagem, que mulheres negras recebam menos anestesia no parto pois elas "são mais fortes", dentre muitos outros. Ou seja, grande parte da ciência (sem nenhuma retratação) mudou o seu discurso, mas a sociedade não mudou a sua prática. O "somos todos humanos" ainda não chegou para grande parcela da população negra e ameríndia deste país. Uma ciência comprometida com os dilemas e tensões sociais do seu tempo necessita ter não só esta consciência como principalmente promover ações que visem reduzir este abismo racial no Brasil e no mundo. Por esta razão, trabalhos desta natureza são tão relevantes e precisam ser incentivados para que mais pessoas se vinculem a pesquisas desta natureza no nosso país e para que conhecimentos produzidos neste campo sejam largamente socializados nas salas de aula, contribuindo para promover uma educação verdadeiramente democrática.

\section{Referências $^{6}$}

Benite, Anna, Silva, Juvan, \& Alvino, Antônio. (2017). Ferro, Ferreiros e forja: o ensino de química pela lei no 10.639. Educação em Foco. 735-768.

Carneiro, Sueli. (2005). A Construção do Outro como Não-Ser como fundamento do Ser. 2005. 339f. Tese (Doutorado em Educação) - Faculdade de Educação da Universidade de São Paulo, São Paulo.

Cunha, Henrique., Jr. (2010). Tecnologia Africana na Formação Brasileira (1ª ed). Rio de Janeiro, CEAP.

Diop, Cheikh. A. (1983). A origem dos antigos egípcios. In Mokhtar, G. (Org). História Geral da África: A África antiga (pp. 39-70). São Paulo: Ática/ UNESCO.

Dussel, Enrique. (1993). 1492: o encobrimento do outro. A origem do "mito da modernidade”. São Paulo: Vozes.

Fanon, Fanon. (1979). Os Condenados da Terra (2ºd). Rio de Janeiro: Civilização Brasileira.

Fluzin, Philippe. (2004). The Origins of Iron Metallurgy in Africa New light on its antiquity: West and Central Africa. Paris, UNESCO.

6 Nas normas da revista, as referências devem ser apresentadas com as iniciais do primeiro nome das autoras e autores. Como eu trabalho com diversidade nas ciências naturais, costumo inserir o primeiro nome completo para que as pessoas saibam quais as referências de mulheres e de homens, adoto isto como uma postura política de respeito à questão de gênero, pois em virtude do patriarcado e da subestimação da intelectualidade feminina, costuma-se referir as citações sempre no masculino, exemplo: "O Benite”; enquanto, na realidade trata-se de uma mulher... Faço aqui essa explanação da minha escolha. 
Machado, Carlos, \& Loras, Alexandra. (2017). Gênios da humanidade: ciência, tecnologia e inovação africana e afrodescendente. São Paulo: DBA.

Melo, André. (2019). Biodiversidade: narrativas, diálogos e entrelaçamento de saberes da comunidade/escola em um território quilombola do semiárido baiano. 2019. Tese (Doutorado em Ensino, Filosofia e História das Ciências) - Universidade Federal da Bahia/Universidade Estadual de Feira de Santana, Salvador.

Mignolo, Walter. (2004). "Os esplendores e as misérias da "ciência": colonialidade, geopolítica do conhecimento e pluri-versalidade epistêmica". In Santos, B. S. (org.). Conhecimento prudente para uma vida decente: um discurso sobre as ciências revisitado (pp. 667-709). São Paulo, Cortez.

Munanga, Kabenguele, \& Gomes, Nilma. (2006). O negro no Brasil de hoje. São Paulo: Global.

Nascimento, Elisa. (1996). Introdução às antigas civilizações africanas, In Sankofa: matrizes africanas da Cultura Brasileira, Rio de Janeiro: Universidade do Estado do Rio de Janeiro.

Pinheiro, Bárbara, Rosa, Katemari. (2018). Descolonizando saberes: a Lei 10639/2003 no ensino de ciências. São Paulo: Livraria da Física.

Pinheiro, Juliano. (2016) Possibilidades de diálogos sobre questões étnico-raciais em um grupo do PIBID - Química. Tese (Doutorado em Química - UFU). Instituto de Química, Universidade Federal de Uberlândia, Uberlândia, Brasil.

Pinheiro, Juliano, \& Silva, Rejane. (2008). Mobilização de Saberes Docentes no processo de produção de Objetos de Aprendizagem que atendem a lei 10.639/03. XIV Encontro Nacional de Ensino de Química (XIV ENEQ). Curitiba/PR.

Pinheiro, Juliano, Henrique, Hélen, \& Santos, Ênio. (2010). A (in)visibilidade do negro e da história da África e Cultura Afro-Brasileira em livros didáticos de Química. XV Encontro Nacional de Ensino de Química (XV ENEQ). Brasília (DF), 2010.

Quijano, Anibal. (2005). Colonialidade do poder, eurocentrismo e América Latina. In: Lander, E. (Org.). A colonialidade do saber: eurocentrismo e ciências sociais (pp. 345392). Buenos Aires: Consejo Latinoamericano de Ciencias Sociales - CLACSO.

Quijano, Anibal. (2010). Colonialidade do Poder e Classificação Social. In Santos, B. S., \& Meneses, M. P. Epistemologias do Sul (pp. 73-118). São Paulo, Cortez.

Rosa, Katemari. (2016). A (pouca) presença de minorias étnico-raciais e mulheres na construção da ciência. In M. D. Garcia, M. A. Auth, \& K. Takahashi. (Org.). Enfrentamentos do Ensino de Física na Sociedade Contemporânea, 1a ed., (pp. 619-632). São Paulo: Livraria da Física. 
Santos, Enio, Rodrigues-Filho, Guimes, \& Amauro, Nicea. (2013). Dificuldades na aplicação de materiais didáticos digitais que trabalham assuntos estudados pela Química em conformidade com a Lei no 10.639/03. IX Encontro Nacional de Pesquisa em Educação em Ciências - IX ENPEC Águas de Lindóia (SP).

Santos, João, Rodrigues-Filho, Guimes, \& Amauro, Nicea. (2016). A educação de jovens e adultos e a disciplina de química na visão dos envolvidos. Química Nova na Escola. 244-250.

Silva, Elton, Garcia, Fabiano, \& Pinheiro, Bárbara. (2018). "Cabelo veio da África junto com os meus santos”: a Química dos cabelos crespos (ou não). XIX Encontro Nacional de Ensino de Química (XIX ENEQ). Rio Branco.

Silva, Henrique, \& Pinheiro, Bárbara. (2018). Produções científicas do antigo Egito: um diálogo sobre Química, cerveja, negritude e outras coisas mais. Revista Debates em Ensino de Química. 2-25.

Silva, Juvan, Alvino, Antônio, Santos, Marciano, Santos, Vander, \& Benite, Anna. (2017). Tem dendê, tem axé, tem Química: Sobre história e cultura africana e afro-brasileira no ensino de Química. Química Nova na Escola, 19-26.

Silva, Renato. (2013). Isto não é Magia; é Tecnologia: subsídios para o estudo da cultura material e das transferências tecnológicas africanas 'num' novo mundo. São Paulo: Ferreavox.

Verrangia, Douglas. (2010). Conhecimentos tradicionais de matriz africana e afrobrasileiranoensinodeCiências:um grandedesafio. RevistaÁfricae Africanidades.705-718.

Walsh, Catherine. (2008). Interculturalidad, plurinacionalidad y decolonialidad: las insurgencias político-epistémicas de refundar el Estado. Tabula Rosa. 9, 131-152.

Bárbara Carine Soares Pinheiro @https://orcid.org/0000-0001-6899-8485

Universidade Federal da Bahia Instituto de Química Salvador, Bahia, Brasil

Submetido em 29 de abril de 2019 Aceito em 02 de Julho de 2019 Publicado em 02 de agosto de 2019 